\title{
Multi-scale object-based fuzzy classification for LULC mapping from optical satellite
}

\section{images}

\author{
Hang T. Do, Venkatesh Raghavan, Luan Xuan Truong, Go Yonezawa
}

\begin{tabular}{|c|l|}
\hline Citation & Spatial Information Research. 27(2); 247-257 \\
\hline Issue Date & 2019-04-08 \\
\hline Published & 2019-02-06 \\
\hline Type & Journal Article \\
\hline Textversion & author \\
\hline Rights & $\begin{array}{l}\text { This is a post-peer-review, pre-copyedit version of an article published in Spatial } \\
\text { Information Research. The final authenticated version is available online at: } \\
\text { https://doi.org/10.1007/s41324-019-00240-w. } \\
\text { This is the accepted manuscript version. } \\
\text { See Springer Nature terms of reuse: } \\
\text { https://www.springer.com/gp/open-access/publication-policies/aam-terms-of-use }\end{array}$ \\
\hline DOI & $10.1007 /$ s41324-019-00240-w \\
\hline
\end{tabular}

Self-Archiving by Author(s)

Placed on: Osaka City University

Do, H.T., Raghavan, V., Truong, L.X. et al. Multi-scale object-based fuzzy classification for LULC mapping from optical satellite images. Spatial Information Research. 27, 247-257 (2019). doi:10.1007/s41324-019-00240-w 


\title{
Multi-scale Object-based Fuzzy Classification for LULC Mapping from Optical Satellite Images
}

\author{
Hang T. Do ${ }^{1}$, Venkatesh Raghavan ${ }^{1}$, Luan X. Truong ${ }^{2}$, Go Yonezawa ${ }^{1}$ \\ ${ }^{1}$ Osaka City University, Japan \\ ${ }^{2}$ Hanoi University of Mining and Geology, Vietnam
}

\begin{abstract}
In this paper, a multi-scale object-based Fuzzy approach is demonstrated for Land use/Land cover (LULC) classification using high-resolution multi-spectral optical RapidEye and IKONOS images of Lao Cai and Can Tho areas in Vietnam respectively. Optimal threshold for segmentation procedure is selected from Rate of Change Local Variance (ROC-LV) graph. Object-based fuzzy approach is implemented to identify LULC classes and LULC initial sets, and then the initial sets are classified to final LULC classes. In case of Lao Cai area, Normalized Difference Vegetation Index (NDVI), Normalized Difference Water Index (NDWI), water index (WI) in objectbased are used to generated water, terrace field classes, and built-up and vegetation sets. NDVI, soil index (SI) and red band are used to distinguish built-up set to building, bare land and road classes. NDVI and RedEgde band are inputs to classify rice field and forest classes from vegetation set. In case of Can Tho area, NDWI and WI are generated to water, vegetation, paddy field classes and built-up set, and then built-up set is classified to building, bare land, road, and paddy field classes. The technique is able to create LULC maps of Lao Cai and Can Tho areas with $(90.8 \%, 0.84)$, and $(92.3 \%, 0.90)$ classification accuracy and kappa coefficient, correspondingly.
\end{abstract}

Keywords: Fuzzy, LULC, Local Variance, Multi-scale segment, Object-based, GRASS GIS

\section{Introduction}

Mapping LULC is essential for environmental monitoring requirements, conservation goals, spatial planning enforcement, or ecosystem-oriented natural re-sources management [1]. High spatial resolution remote sensing data enable to address LULC problem at higher-order in urban/suburban and natural landscapes [2]. Remote sensing imagery, which is widely used for LULC, is structured according to two primary descriptors: spectral and spatial. The original spectral detail can be used directly for LULC classification, but it is often highly correlated together, also contains various external influences such as topographic relief and atmospheric scattering, bringing about ineffective analysis classes. Image-derived features, such as multispectral ratio (spectral index) and measure of spatial structure (spatial index), by redistributing the original information into a more useful form context, should be exploited to produce accurate classification maps [3, 4].

Object-based analysis has been gaining importance in the fields of remote sensing, especially for high spatial resolution image processing [5]. The approach may be more appropriate than traditional pixel-based approach since it does not operate directly on individual pixels but on groups of contiguous pixels, allows exploiting spectral-spatial 
data [6-9]. Image objects are generated by image segmentation process in which scale parameter is a key parameter to partition the image into objects. Optimal scale of image segmentation can be taken from ROC-LV graph [10]. One scale of image segmentation may lead to over-segmentation for some LULC classes but under-segmentation for other in complex LULC categories due to difference in structure of the classes [11]. Therefore, multi-scale segmentation may allow the classifier to better LULC.

Fuzzy classification has been applied in remote sensing for natural features which are dispersed gradually and continuously over space [12]. The phenomenon regularly leads to the presence of some LULC classes within a single pixel in remote sensing imagery. Fuzziness is a term to reveal continuously varies LULC classes in natural phenomena, such as road and building [13]. Fuzzy classification approach was introduced to solve fuzziness problem $[14,15]$.

Toward that end, multi-scale object-based fuzzy classification method has been explored to indentify LULC maps. To evaluate the effectiveness of proposed method; two experiments are carried on high spatial resolution RapidEye and IKONOS data.

\section{Methodology}

\subsection{Study areas and data}

Study areas of the study are Lao Cai area and Can Tho area in Vietnam. Lao Cai is a mountainous area in the north where main LULC classes are water, building, bare land, road, terrace field, paddy field and forest. Can Tho is a flat and low-lying land in the south of Vietnam where LULC classes are water, building, rice field, road and vegetation (mangrove plants and other lowland plants and grasses) (Fig 1).

The remotely sensed data are used include RapidEye image of Lao Cai area and IKONOS image of Can Tho area. 5-meter RapidEye imagery is optical multispectral imagery with five distinct bands: blue, green, red,RedEgde and NIR [16], especially RedEdge band is a useful data for vegetation classification [17, 18].1-meter generation IKONOS imagery consists of four single bands:blue, green, red, and NIR [19].

Spectral indices of remotely sensed image are the combinations of surface reflectance at multispectral information that indicate relative dominance of features of interest such as vegetation, water, soil [20]. Spectral indices usedfor Fuzzy classification in this study include Normalized Difference Vegetation Index (NDVI), Normalized Difference Water Index (NDWI) [21] and Vegetation-Soil-Water index (VSW) [22] which are derived as ratios from original channels. VSW illustrates Soil Index (SI), Vegetation Index (VI) and Water Index (WI) by defining distance between a target point to Soil line, Water line and Vegetation line in Red-NIR bands spectral space correspondingly.

Smoothness Index $(\mathrm{SmI})$ is one of shape heterogeneity parameters which represents the smooth degree of the object obtained in the process [23] the spatial index calculated by: 


$$
\mathrm{SmI}=\frac{\mathrm{P}}{\sqrt{\mathrm{S}}}
$$

Where: $\mathrm{P}$ is perimeter of segment and $\mathrm{S}$ is area of segment.

A number of 144669 sample points generated from 1:25000 scaled forest map (2014) of Lao Cai area is separated to three sets: training, validation and test set. The Can Tho dataset has 216367 sample points which are selected by manually based on IKONOS image and Google Earth.

\subsection{Multi-scale image segmentation}

Image segmentation techniques have been used much frequently to process satellite sensor data, which is the process of grouping neighbor pixels to objects which have similar digital values [24]. The process possesses intrinsic size, shape and geographic relationship with the imprecise nature of the data [25]. "Region growing and merging" segmentation algorithm which contains region growing and merging processes is used in this study. Region growing process groups neighboring similar pixels into regions while merging process merges similar neighboring regions will be merged to larger objects by comparing the similarity between current region and its neighbors with input threshold [26, 27]. The threshold value which must be smaller than 1 and larger than 0 , defines the level of segmentation.

Local Variance (LV) is measured as the mean of the value of standard deviation (SD) in a small neighborhood over the entire image [28]. The value shows the relationship between spatial structure of images, size of the objects in the real world and pixel resolution: if the spatial resolution is considerably finer than the objects in the scene, most of the SD in the image will be highly correlated with their neighbors and LV value will be low; if the objects approximate the size of the resolution cells, then the likelihood of neighbors being similar decreases and the LV value rises. In case of object-based analysis, instead of calculate SD in a moving window, LV is defined by SD value of pixels inside a segment [29].

Segmentation on multiple spectral bands of remote sensing data is desirable to take full advantage of the data. Mean value of LV (MeanLV) of segmentation level is created by computing the ratio between the summary of the LVs for each band $\mathrm{i}\left(\mathrm{LV}_{\mathrm{i}}\right)$ and the number of spectral bands (n) [30]:

$$
\text { MeanLV }=\frac{\sum_{\mathrm{n}}^{\mathrm{i}} L V_{\mathrm{i}}}{\mathrm{n}}
$$

To assess the dynamics of MeanLV value of different segmentation levels, Rate of Change of Local Variance (ROC-LV) [31] measurement is used:

$$
\text { ROC }-L V=\frac{100 *\left(M_{\text {eanLV }}-\text { MeanLV }_{j-1}\right)}{\operatorname{MeanLV}_{j-1}}
$$

Where: $\mathrm{j}$ is value of threshold, MeanLV $\mathrm{j}_{\mathrm{j}}$, Mean $\mathrm{LV}_{\mathrm{j}-1}$ are Mean local variance at a given level and previous level, correspondingly. 
Peaks in the ROC-LV graph show the object levels at which the image can be segmented in the most appropriate manner, relative to data properties at some scene levels. At these peaks, the segments match the types of objects characterized by equal degrees of homogeneity [10].

In this study, ROC-LV graphs are produced in PyGRASS- an object-oriented Python application programming interface for GRASS GIS[32] by the authors.5 and 4 are values of number of bands $n$ of RapidEye data and IKONOS data, respectively. Values of threshold $\mathrm{j}$ range from 0.01 to 0.4 ; step is 0.01 for both RapidEye and IKONOS data. Peaks of the graphs are considered to select optimal scale of segmentation.

\subsection{Fuzzy classification}

Fuzzy logic is the soft computing that allows identification of multiple and partial membership of LULC classes to resolve mixed pixels existence problem. Fuzzy membership which is termed as fuzzy set illustrates the strength of class membership of a pixel of LULC classes (membership degree), where the value ranges between 0 to $1[33]$.

Scherer [34] described Fuzzy set A in space $\mathrm{X}$ is as follow:

$$
\mathrm{A}=\left\{\left(\mathrm{x}, \mu_{\mathrm{A}}(\mathrm{x})\right) ; \mathrm{x} \in \mathrm{X}\right\}
$$

Where $\mathrm{X}$ is the universe of the range of possible values for describing imprecise or vague data, $\mathrm{A} \subseteq \mathrm{X}, \boldsymbol{\mu}_{\mathrm{A}}: \mathrm{X} \rightarrow$ $[0,1]$ is the membership function of fuzzy set $A$ which assigns to each element $\mathrm{X} \in \mathrm{X}$ its membership degree to the fuzzy set A.

In particular, there are some standard forms of membership functions such as Gaussian and Triangular functions. Consider $\dot{x}$ is the middle and $\sigma$ describes the width of the Gaussian curve, the function of Gaussian membership $\mu_{\mathrm{A}}$ is expressed by the formula [34]:

$$
\mu_{\mathrm{A}}(\mathrm{x})=\exp \left(-\left(\frac{\mathrm{x}-\dot{x}}{\sigma}\right)^{2}\right)
$$

In the case of Triangular membership $\mathrm{T}(\mathrm{x} ; \mathrm{a}, \mathrm{b}, \mathrm{c})$ where $\mathrm{a}$ is lower limit, $\mathrm{c}$ is upper limit, and $\mathrm{b}$ is a value where $\mathrm{a}<\mathrm{b}<\mathrm{c}$. In the particular case, when $\mathrm{b}=(\mathrm{a}+\mathrm{c}) / 2$, then the function $\mathrm{T}$ takes the form of [34]:

$$
\mathrm{T}(\mathrm{x} ; \mathrm{a}, \mathrm{b}, \mathrm{c})=\left\{\begin{array}{c}
0, \mathrm{x} \leq \mathrm{a} \\
2\left(\frac{\mathrm{x}-\mathrm{a}}{\mathrm{c}-\mathrm{a}}\right)^{2}, \mathrm{a}<\mathrm{x} \leq \mathrm{b} \\
1-2\left(\frac{\mathrm{x}-\mathrm{c}}{\mathrm{c}-\mathrm{a}}\right)^{2}, \mathrm{a}<\mathrm{x} \leq \mathrm{b} \\
1, \mathrm{x}>\mathrm{c}
\end{array}\right.
$$

Fuzzy classification is the set of procedure which forms fuzzy rule for classification. The system consists of four elements: rule base, fuzzification, inference and defuzzification.

- Rule base 
Rule base is a set of fuzzy rules $R^{(k)}, \mathrm{k}=1, \ldots, \mathrm{N}$ of the form:

$R^{(k)}:$ IF $\mathrm{x} 1$ is $A_{1}^{k}$ AND .... AND xn is $A_{n}^{k}$ THEN y 1 is $B_{1}^{k}$ AND .... AND y is $B_{m}^{k}$

$\mathrm{N}$ is number of fuzzy rules, $A_{i}^{k}, B_{j}^{k}$ are fuzzy sets such as:

$$
\begin{aligned}
& A_{i}^{k} \subseteq X_{i} \subset R, \mathrm{i}=1, \ldots, \mathrm{n} \\
& B_{j}^{k} \subseteq Y_{j} \subset R, \mathrm{j}=1, \ldots, \mathrm{m}
\end{aligned}
$$

$\mathrm{x}_{1}, \ldots, \mathrm{x}_{\mathrm{n}}$ are input variables and $\mathrm{y}_{1}, \ldots, \mathrm{y}_{\mathrm{n}}$ are output variables of the fuzzy model, $X_{i}, Y_{j}$ represent the space of input and output variable correspondingly [34].

- Fuzzification

Fuzzification is used by fuzzy logic operates on fuzzy sets. Some of regular fuzzification methods are Zadeh, product, drastic, Lukasiewicz and operations used for those methods are t-norm (minimum) and t-conorm (maximum)[34]. Zadeh notation can be represented in following equation:

$$
\mu_{\mathrm{A} \rightarrow \mathrm{B}}(\mathrm{x}, \mathrm{y})=\max \left\{\min \left[\mu_{\mathrm{A}}(\mathrm{x}), \mu_{\mathrm{B}}(\mathrm{y})\right], 1-\mu_{\mathrm{A}}(\mathrm{x})\right\}
$$

- Inference

Inference is obtained from a fuzzy set $\mathrm{A} \subseteq \mathrm{X}=\mathrm{X}_{1} \times \mathrm{X}_{2} \times \ldots \times \mathrm{X}_{\mathrm{n}}$. Output of the process is fuzzy set $\mathrm{B}^{\mathrm{k}}$. Membership function of $\mathrm{B}^{\mathrm{k}}[34]$ is shown below:

$$
\mu_{\bar{B}} k(y)=\sup _{x \in X}\left[\mu_{A^{\prime}}(X)^{T} * \mu_{A^{k} \rightarrow B^{k}}(X, y)\right]
$$

- Defuzzification

Defuzzification is the process for mapping output fuzzy set $B^{k}$ of inference to single value $y \in Y$. Some methods to establish ýare: centroid (centre average), bisector (centre of gravity or centre of area), centre of sums and maximum membership function etc[34]. Bisector method calculates ýusing:

$$
\bar{y}=\frac{\int y \mu_{B^{\prime}}(y) d y}{\int \mu_{B^{\prime}}(y) d y}=\frac{\int y S_{\mathrm{k}=1}^{N} \mu_{\bar{B}}(y)}{\int S_{\mathrm{k}=1}^{N} \mu_{\bar{B}}(y)}
$$

Fuzzy system classification module named "i.fuzzy.system" in GRASSGIS [35] has been used to generate the LULC maps. Fuzzy sets and fuzzy rules are stored on Fuzzy variable file and rule file correspondingly. Fuzzy sets, Fuzzy rules, inputs and outputs of Fuzzy classification are identified based on histogram distribution of training data of original bands and indices. Membership functions of input indices and output classes were setup as Gauss shape ("s-shape") and Triangular shape ("linear"), respectively. Zadeh fuzzification and Bisector defuzzification are exploited as the algorithms of fuzzy system. The result of fuzzy classification demonstrates the percentage of output 
sets in each object. The value of $50 \%$ is used as threshold to divide these sets separately (e.g. target pixel /object is labelled as water if percentage of water in the pixel/object is equal or higher than $50 \%$ ).

\section{Procedures and results}

\subsection{Lao Cai area classification}

Atmospheric and topographical corrections of RapidEye imagery are applied. Full Lao Cai area is separated to water, terrace field classes, and two sets: built-up and vegetation in object-based at 0.03 of threshold (T). Built-up set in object-based at 0.05 of $\mathrm{T}$ is distinguished to building, bare land and road classes. Rice field and forest classes are categorized from vegetation set in object-based at $\mathrm{T}$ equals 0.07 . Final LULC map is made by combining above classes.

ROC-LV graph of Lao Cai area is created, the first peak of graph is at 0.03 of threshold, second peak is at T equals 0.09 (Fig 2a). Samples of segmentation boundary at the two peaks are shown in Fig 3a, 3b: at $\mathrm{T}=0.03$, oversegmentation happens when a terrace area (grey color) is segmented to several segments; at $\mathrm{T}=0.09$, undersegmentation phenomenon occurs when terrace area and vegetation area (red color) are grouped in one segment. Since over-segmented areas are able to be merged into desired objects in the classification step but under-segmented areas cannot, optimal threshold of segmentation may the biggest value of peaks of ROC-LV graph at that no undersegmentation phenomenon happens [36]. As a result, the first peak of ROC-LV at 0.03 is used as optimal threshold for segmentation. NDVI, NDWI, WI and blue band, and Fuzzy rule R1, R2, R3 and R4 (Table 1) are used to investigate water and terrace field classes, built-up and vegetation sets. Overall accuracy (OA) is $97.1 \%$ and Kappa coefficient is 0.94 , higher than classification result at second peak of ROC-LV at 0.09 (OA is $96.1 \%$ and Kappa is $0.92)$.

To classify built-up set, ROC-LV graph of the set is shown in Fig 2b. Samples of segment boundary of the first and second peaks are shown in Fig 3c, 3d. To ignore under-segmentation phenomenon which occurs at second peak (road and building are grouped in a segment), the first peak at 0.05 of ROC-LV graph is chose as optimal threshold. SI, SmI and WI in object-based are inputs of Fuzzy classification, rules R5, R6 and R7 (Table 1) are used to identify building, bare land and road classes. OA is $88.8 \%$ and Kappa of the classification is 0.78 . The result is better than classification result at second peak of ROC-LV graph at 0.07 (OA is $85.7 \%$ and Kappa is 0.76 ).

ROC-LV graph of vegetation set is generated (Fig 2c) and samples of segmentation boundary of first, second and third peaks are shown in Fig 3e, 3f, 3g. Since under-segmentationoccursin forest and rice field classes at third peak, while over-segmentation phenomenon happens in forest class (inside black square), the second peak at 0.07 of ROC-LV is chose as optimal scale-segment Fuzzy classifier analyzes NDVI and RedEdge band using rules R8, R9 (Table 1) to classify paddy field and forest classes. The OA is $93.6 \%$ and Kappa is 0.68 . The result is the best in comparison with the classification result at first peak at 0.05 (OA is $92.7 \%$ and Kappa is 0.64 , and the third peak at 0.09 (OA equals $91.5 \%$ and Kappa equals 0.58). 
LULC map of Lao Cai area is built by merging seven LULC classes from above classifications (Fig 4). The final classification result shows that water, paddy field, forest, terrace field and building get high accuracies as $96.9 \%, 93.1 \%, 92 \%, 87.9 \%$ and $86.5 \%$ correspondingly. While accuracy of bare land class is $82.6 \%$, the value of road class is $69 \%$ only, because many building pixels are classified as road due to similarity on spectral detail of the two classes. Overall accuracy of the classification is $90.8 \%$ and Kappa is 0.84 (Table 2).

\subsection{Can Tho area classification}

Can Tho area object-based images at 0.04 of $\mathrm{T}$ is classified to paddy field, water, vegetation classes and set of building-road-bare land-rice field (BRBR). Segment image of BRBR set at 0.07 of $\mathrm{T}$ is generated to building, bare land, road, and paddy field classes. Six classes are merged to final LULC map of the area.

ROC-LV graph of whole area is generated (Fig 5a). To ignore under-segmentation phenomenon in vegetation class and built-up set at second peak, the first peak at 0.04 of ROC-LV graph is selected as optimal segment threshold. Segment-based of WI and NDWI are generated as input of Fuzzy classification to distinguish to water, rice field, vegetation classes and BRBR set using R10, R11, R13 and R14 rules (Table 3).Confusion matrix of classification is shown in Table 4. The classification result at the peak achieves higher overall accuracy and Kappa (93.9\% and 0.91 respectively) than second peak at 0.08 (OA is $93.2 \%$, Kappa is 0.90 ).

ROC-LV graph of BRBR set is shown in Fig 5b. Optimal threshold of built-up set is setup as 0.05 as the first peak of the ROC-LV graph since under-segment happens in road and building classes. SI, SmI, NDWI and blue band in segment-base are input of Fuzzy classification using R14, R15, R16 and R17 rules (Table 3) to classify building, road, bare land and rice field. OA and Kappa of the classification are $85.5 \%$ and 0.78 , respectively. The classification result at the threshold is better than at second peak of ROC-LV graph at 0.08 (OA equals $82.1 \%$ and Kappa equals 0.73).

Final LULC map of Can Tho area is generated by combining water, bare land, road, building, and paddy field and vegetation classes from above classification steps (Fig 6). Confusion matrix and classification accuracy is shown in Table 4. Water, rice field and vegetation classes show high accuracy values, as 98.8\%, 96.9\% and 94.7\%, respectively. Accuracies of bare land, road and building classes are lower: 81.9\%, 86.2\% and 80.2\% correspondingly due to mixing problem among these three classes. Overall accuracy of the classification is $92.3 \%$ and kappa coefficient is 0.90 .

\section{Conclusions}

In this paper we present a multi-scale object-based fuzzy approach for LULC classification from high resolution optical images data. ROC-LV graph is useful to define optimal threshold for segmentation process. Information of original bands, spectral and spatial indices is used for fuzzy classification. Fuzzy set and fuzzy rule are generated and adjusted based on training set histogram distribution and validation set respectively, while test set is applied to evaluate classification accuracy .Threshold value at the first peak of ROC-LV graph is selected for 
segmentation whole study area and built-up set while the second peak is the optimal scale for vegetation set. Fuzzy classification in object-based approach is used to distinguish LULC classes and LULC sets, then again employed to classify final LULC classes from these sets. The techniques present excellent results with 90.9\%, 0.84 and 92.3\%, 0.90 accuracies and Kappa coefficient of Lao Cai and Can Tho areas, correspondingly. Further work is needed on improving accuracies of building and road classes, and categorizing between different types of vegetation class (for Can Tho area, such as mangrove, grass, vegetable, and fruit tree) and forest class (for Lao Cai area, according to species and density).

\section{Acknowledgement}

We are deeply grateful to Dr. Ho Dinh Duan and Dr. Vinayaraj Poliyapram for their comments which are valuable in improving the manuscript. We also thank the anonymous reviewers for their critical and constructive suggestions. The first author would like to express gratitude to Nishimura International Scholarship Foundation (NISF) for award of fellowship to pursue her doctoral research.

\section{Author Contributions}

This research was mainly prepared and performed by Hang T. Do and Venkatesh Raghavan. Hang T. Do and Venkatesh Raghavan contributed with ideas and designing the data processing workflow. Luan X. Truong and Go Yonezawa provided inputs about data processing methodology and field validation of results and revising of the manuscript.

\section{References}

1. Trincsi, K., Pham, T. T. T., \&Turner, S. (2014). Mapping mountain diversity: Ethnic minorities and land use land cover change in Vietnam's borderlands. Land Use Policy, 41, 484-497.

2. Rogan, J., \&Chen, D.M. (2003). Remote sensing technology for mapping and monitoring land-cover and landuse change. Progress in Planning, 61, 301-325.

3. Shackelford, A. K., \& Davis, C. H. (2003). A Hierarchical Fuzzy classification Approach for High-Resolution Multispectral Data over Urban Areas. IEEE Transactions on Geoscience and Remote Sensing, 41(9), 1920-1932.

4. Schowengerdt, R. A. (2007). Remote sensing: Models and methods for image processing, $3^{\text {rd }}$ edition. USA: Elsevier.

5. Blaschke, T., Burnett, C., \& Pekkarinen, A. (2004). Image Segmentation Methods for Object-based Analysis and Classification. In: Jong S.M.D., Meer F.D.V. (eds) Remote Sensing Image Analysis: Including The Spatial Domain. Remote Sensing and Digital Image Processing, 5. Springer, Dordrecht.

6. Benz, U.C., Hofmann, P., Willhauck, G., Lingenfelder, I., \& Heynen, M. (2004). Multi-resolution, objectoriented fuzzy analysis of remote sensing data for GIS-ready information. ISPRS Journal of Photogrammetry and Remote Sensing, 58(3-4), 239-258.

7. Van der Werff, H.M.A., \& Van der Meer, F.D. (2008). Shape-based classification of spectrally identical objects. ISPRS Journal of Photogrammetry and Remote Sensing, 63(2), 251-258. 
8. Wuest, B., \& Zhang, Y. (2009). Region based segmentation of QuickBird multispectral imagery through band ratios and fuzzy comparison. ISPRS Journal of Photogrammetry and Remote Sensing, 64(1), 55-64.

9. Gamanya, R., De Mmaeyer, P., \& De Dapper, M. (2009). Object-oriented change detection for the city of Harare, Zimbabwe. Expert Systems with Applications, 36(1), 571-778.

10. Dragut, L., Tiede, D., \& Levick, S. R. (2010). ESP: A tool to estimate scale parameter for multiresolution image segmentation of remotely sensed data. International Journal of Geographical Information Science, 24(6), 859871.

11. Myint, S.W., Gober, P., Brazel, A., Grossman-Clarke, S., \& Weng, Q. (2011). Per-pixel vs. object-based classification of urban land cover extraction using high spatial resolution imagery. Remote sensing of environment, 115(5), 1145-1161.

12. Lizarazo, I., \& Barros, J (2010). Fuzzy Image Segmentation for Urban Land-Cover Classification. Photogrammetric Engineering \& Remote Sensing, 76(2), 151-162.

13. Wood, T.F., \& Foody, G. M. (1993). Using cover-type likelihoods and typicalities in a geographic information system data structure to map gradually changing environments. Landscape Ecology and GIS, 141-146.

14. Foody, G.M. (1995). Cross-entropy for the evaluation of the accuracy of a fuzzy land cover classification with fuzzy ground data. ISPRS Journal of Photogrametry and Remote Sensing, 50, 2-12.

15. Wang, F. (1990). Improve remote sensing imagery analysis through fuzzy information representation. Photogrammetric Engineering and Remote Sensing, 56, 1163-1169.

16. Satellite Imaging Corporation. RapidEye Satellite Sensors. https://www.satimagingcorp.com/satellitesensors/other-satellite-sensors/rapideye/. Accessed 16 December 2018.

17. Tigges, J., Lakes, T., \& Hostert, P. (2013). Urban vegetation classification: Benefit of multitemporal RapidEye satellite data. Remote Sensing of Environment, 136, 66-75.

18. Kross, A., McNairn, H., Lapen, D., Sunohara, M., \& Champagne, C. (2015). Assessment of RapidEye vegetation indices for estimation of leaf area index and biomass in corn and soybean crops. International Journal of Applied Earth Observation and Geoinformation, 34, 235-248.

19. Satellite Imaging Corporation. IKONOS Satellite Sensor.https://www.satimagingcorp.com/satellitesensors/ikonos/. Accessed 16 December 2018.

20. Kushida, K., Yongwon K., Tsuyuzaki, S., \& Fukuda, M. (2009). Spectral vegetation indices for estimating shrub cover, green phytomass and leaf turnover in a sedge-shrub tundra. International Journal of Remote Sensing, 30(6), 1651-1658.

21. Gao, B.C. (1996). NDWI - A normalized difference water index for remote sensing of vegetation liquid water from space. Remote Sensing of Environment, 58, 257-266.

22. Yamagata, Y., Sugita, M., \& Yasuoka, Y. (1997). Development of Vegetation-Soil-Water Index algorithms and applications. Journal of the Remote Sensing Society of Japan, 17(1), 54-64.

23. Shao, P., Yang, G., Niu, X., Zhang, X., Zhan, F., \& Tang, T. (2014). Information Extraction of High-Resolution Remotely Sensed Image Based on Multiresolution Segmentation. Sustainability, 6, 5300-5310. 
24. Blaschke, T., Burnett, \& C., Pekkarinen, A. (2004). Image Segmentation Methods for Object-based Analysis and Classification. In: Jong S.M.D., Meer F.D.V. (eds) Remote Sensing Image Analysis: Including The Spatial Domain. Remote Sensing and Digital Image Processing, 5. Springer, Dordrecht.

25. Hay, G.J., Marceau, D.J., Dube, P.,\& Bouchard, A. (2004). A multi-scale framework for landscape analysis: Object-specific analysis and up scaling. Landscape Ecology, 16(6), 471-490.

26. Haralick, R.M., \&Shapiro, L.G. (1985). Image segmentation techniques. Computer vision, graphics, and image processing, 29(1), 100-132.

27. Fu, K.S., \& Mui, J.K. (1981). A survey on image segmentation. Pattern Recognition, 13(1), 3-16.

28. Woodcock, C. E., \& Strahler, A. H. (1987). The factor of scale in remote sensing. Remote Sensing of Environment, 21(3), 311-332.

29. Kim, M., Madden, \&M., Warner, T. (2008). Estimation of optimal image object size for the segmentation of forest stands with multispectral IKONOS imagery. In: T. Blaschke, S. Lang, and G.J. Hay, eds. Object-based image analysis-spatial concepts for knowledge driven remote sensing applications. Berlin: Springer, 291-307.

30. Dragut, L., Csillik, O., Eisank, C., \& Tiede, D. (2014). Automated parameterization for multi-scale image segmentation on multiple layers. ISPRS Journal of Photogrammetry and Remote Sensing, 88, 119-127

31. Bauer, R. J., \& Dahlquist, J. R. (1998). Technical market indicators: analysis and performance. New York: Wiley.

32. Osgeo.org. PyGRASS documentation. https://grass.osgeo.org/grass70/manuals/libpython/pygrass_index.html. Accessed 25 December 2018.

33. Zhang, J., \&Foody, G.M. (1998). A fuzzy classification of sub-urban land cover from remote sensed imagery. International Journal of Remote Sensing, 19(14), 2721-2738.

34. Scherer, R. (2012). Multiple Fuzzy Classification Systems. Springer Heidelberg New York Dordrecht London.

35. Jasiewicz, J. (2010) A new GRASS GIS fuzzy inference system for massive data analysis. Computers \& Sciences, doi:10.1016/j.cageo.2010.09.008.

36. Neubert, M., Herold, H., \& Meinel, G. (2008). Assessing image segmentation quality - concepts, methods and application. In: Blaschke T., Lang s., Hay G.J. (eds) Object-Based Image Analysis. Lecture Notes in Geoinformation and Cartography. Springer, Berlin, Heideberg. 


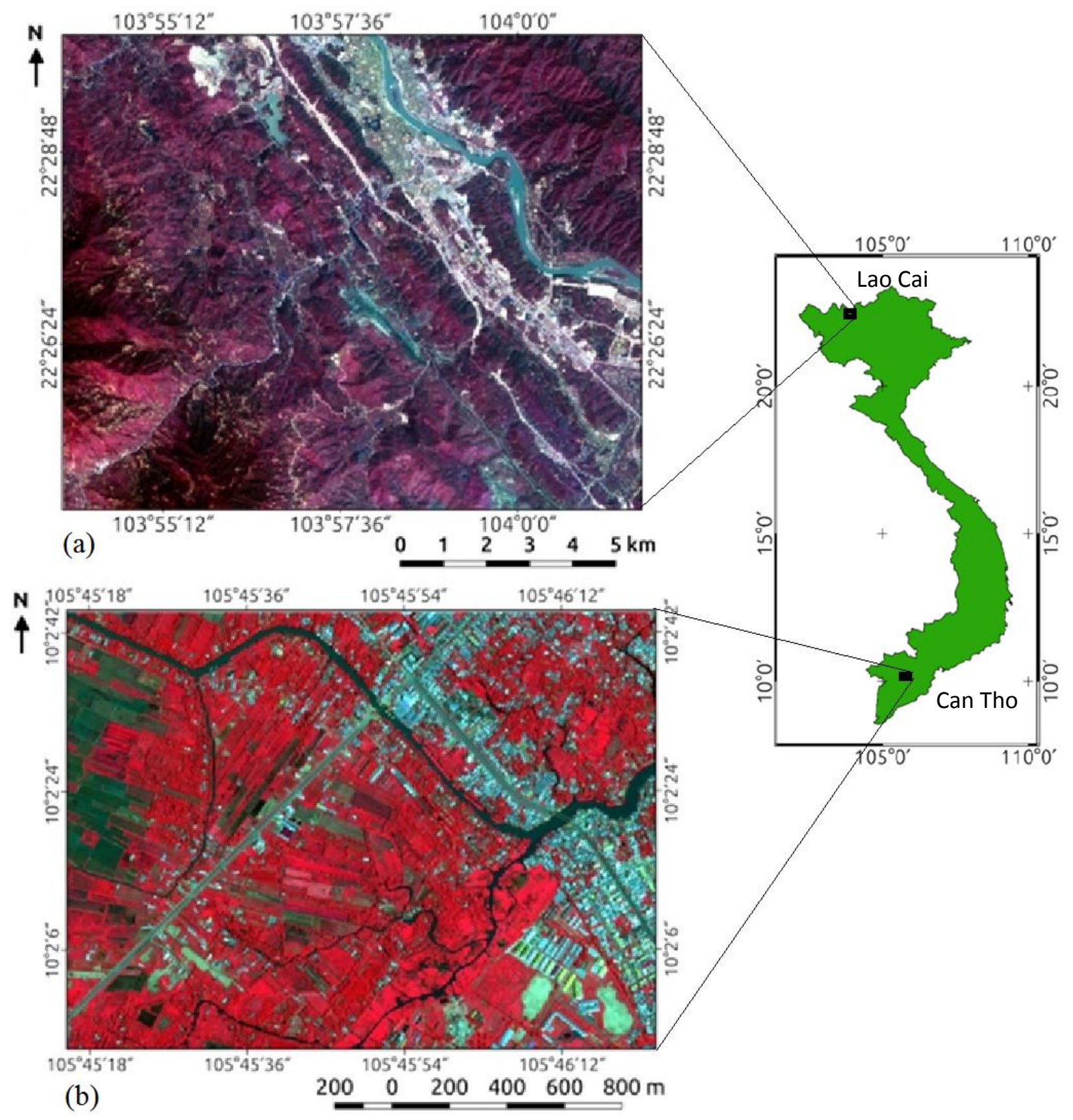

Fig 1 Study area: (a) Lao Cai, (b) Can Tho 


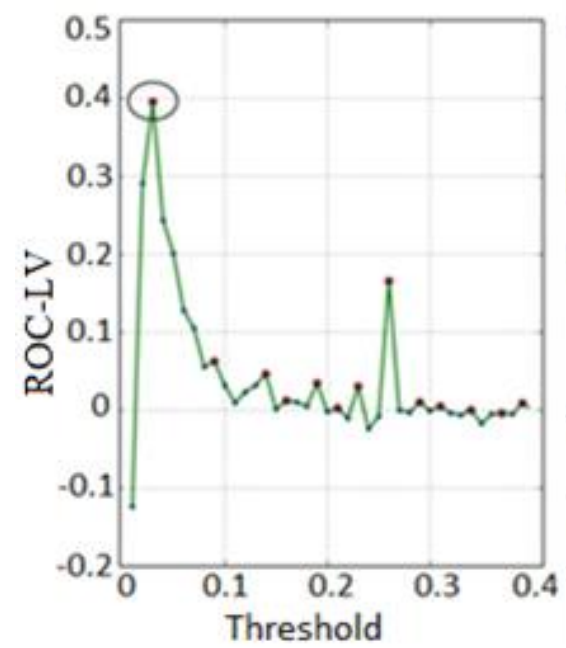

(a)

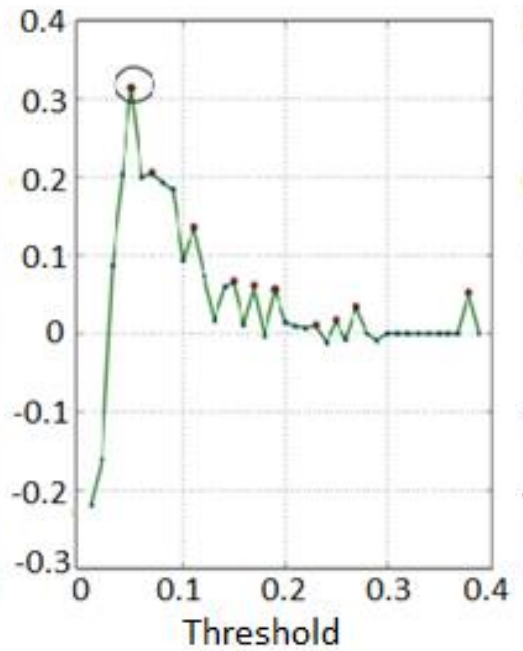

(b)

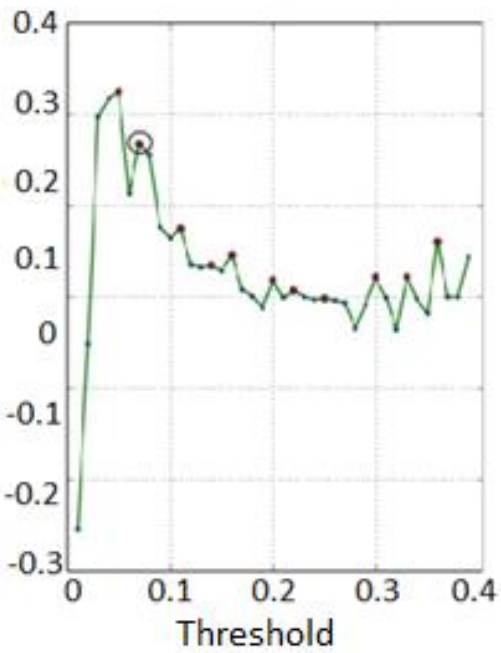

(c)

Fig 2 ROC-LV graphs of Lao Cai area of (a) whole area, (b) built-up set, (c) vegetation set. Thresholds 0.03, 0.05, 0.07 are selected for segmentation correspondingly.

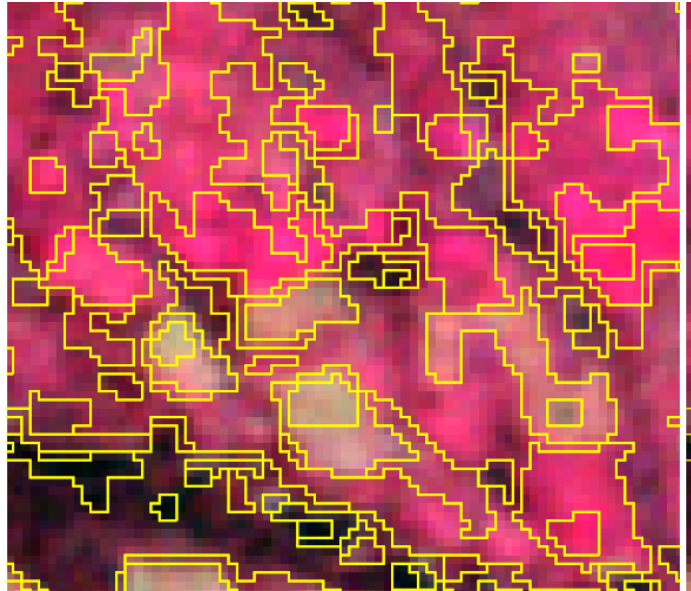

(a) $\mathrm{T}=0.03$

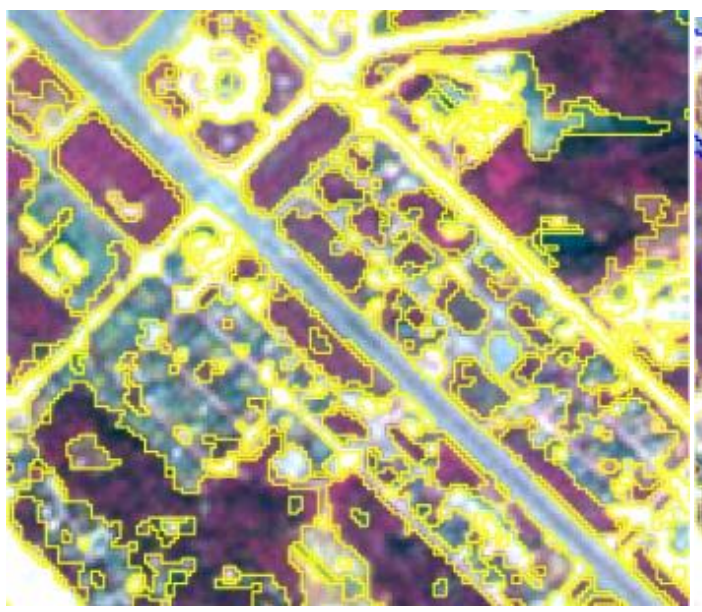

(c) $\mathrm{T}=0.05$

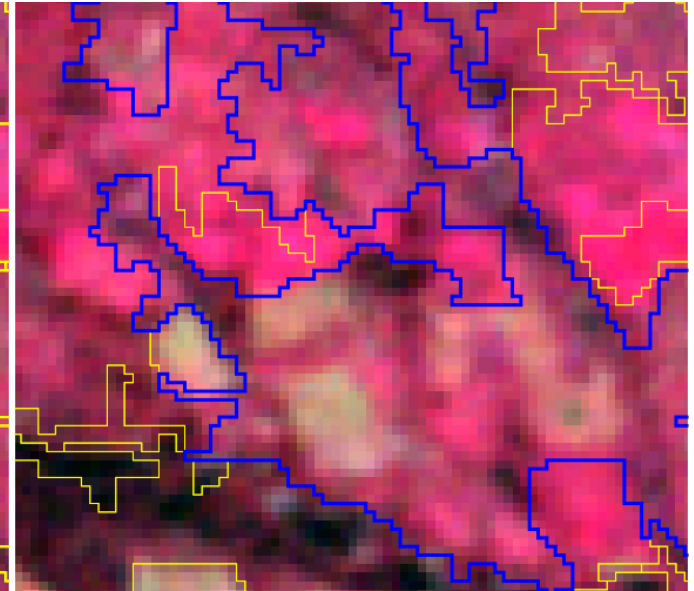

(b) $\mathrm{T}=0.09$

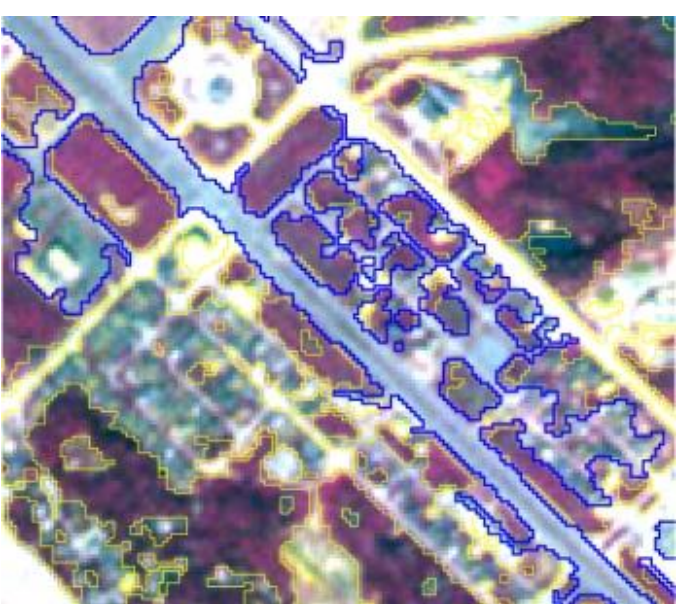

(d) $\mathrm{T}=0.07$ 


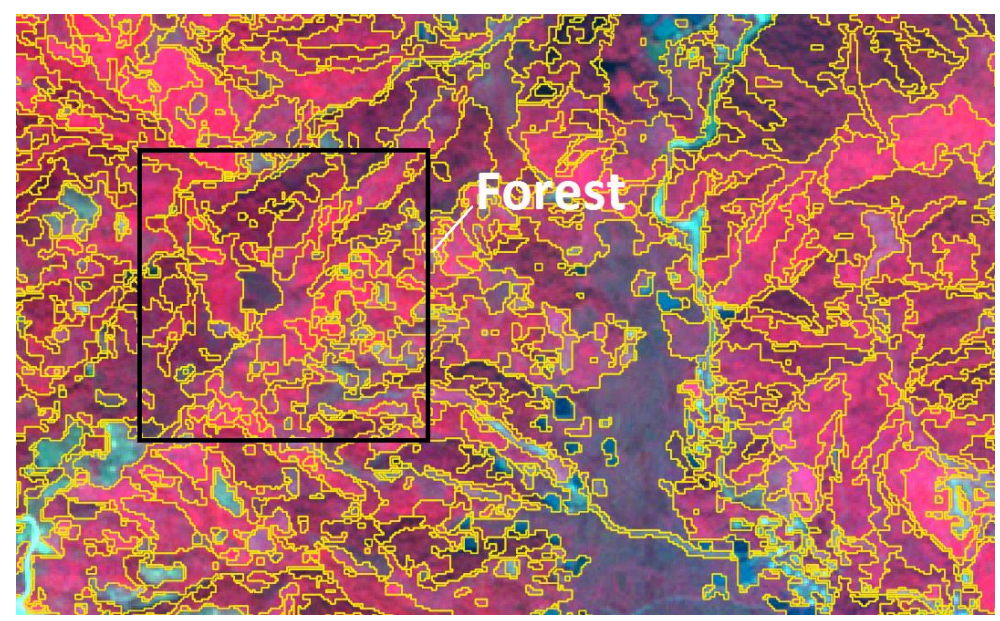

(e) $\mathrm{T}=0.05$

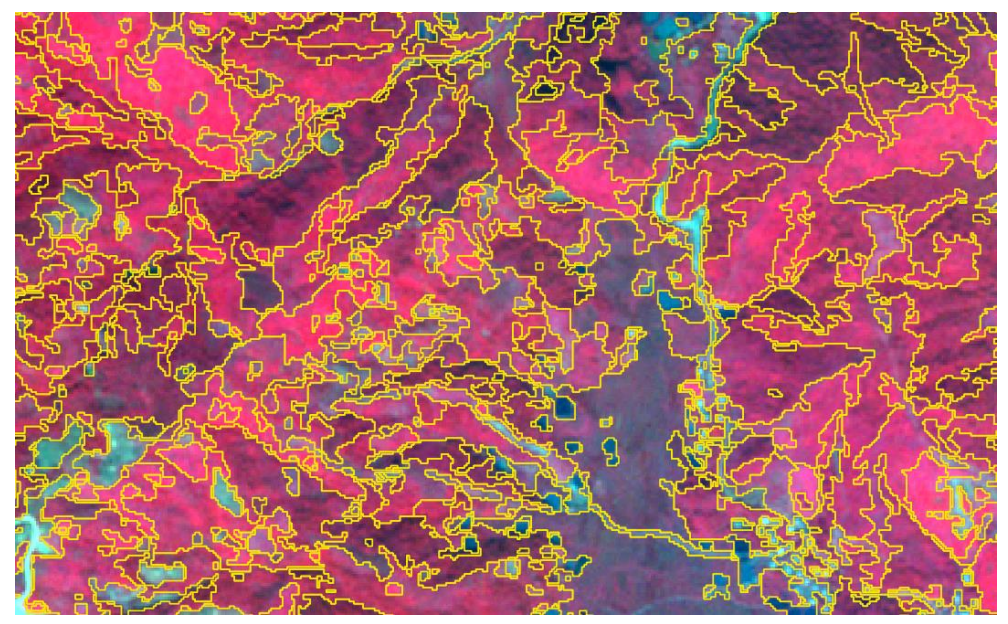

(f) $\mathrm{T}=0.07$

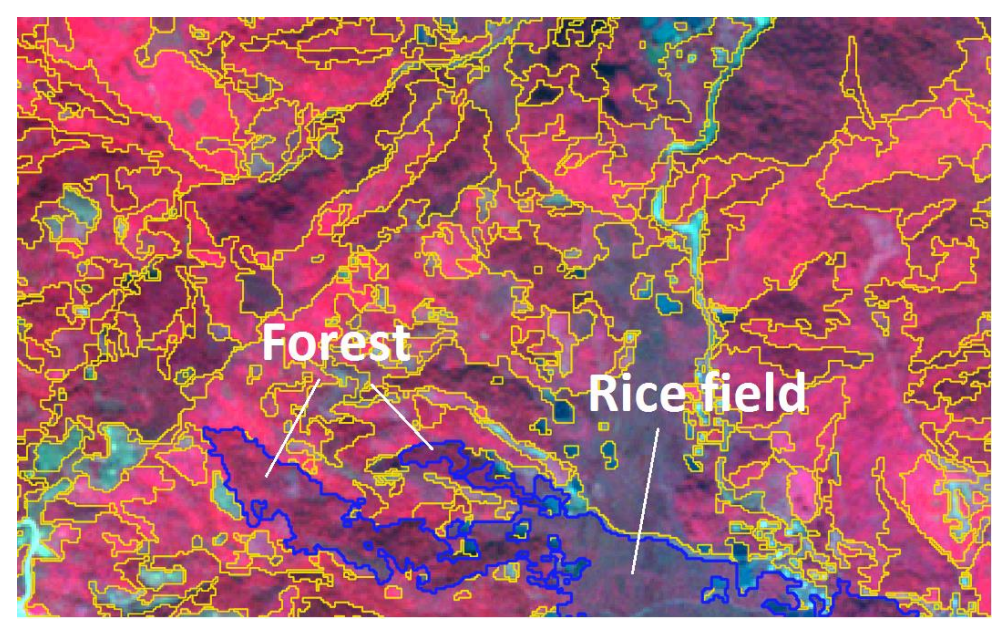

(g) $\mathrm{T}=0.11$

Fig 3 Segmentation boundary of Lao Cai area examples at ROC-LV graphs (a) first and (b) second peak of whole area, (c) first and (d) second peak of built-up set, (e) first, (f)second and (g) third peak of vegetation set. Yellow line is boundary of all segments, blue line is boundary of a single under-segmented area. 


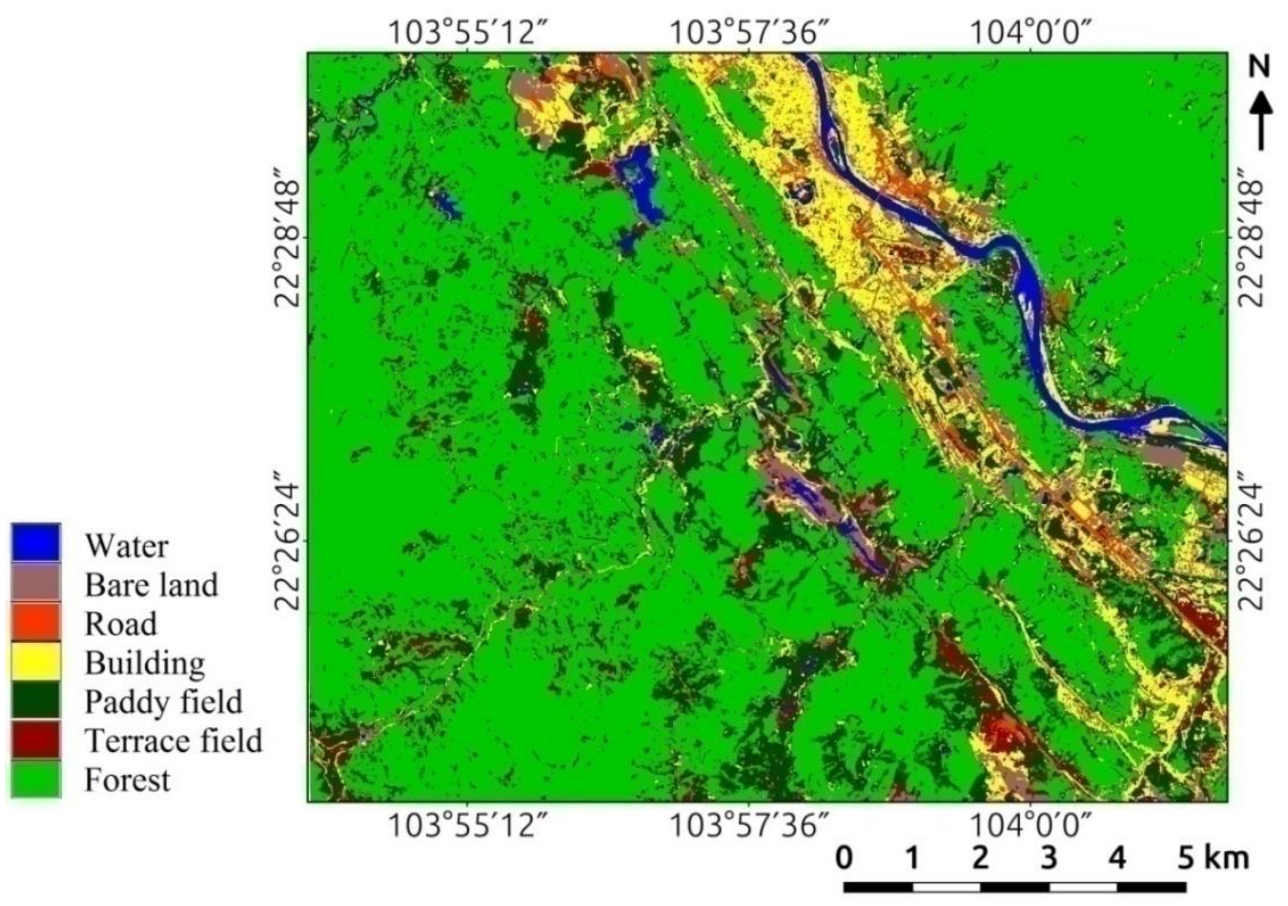

Fig 4 Lao Cai LULC map

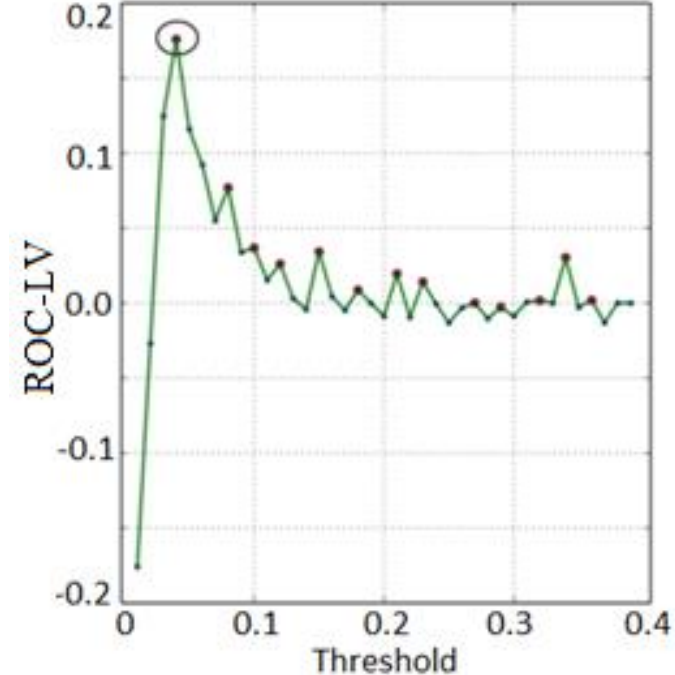

(a)

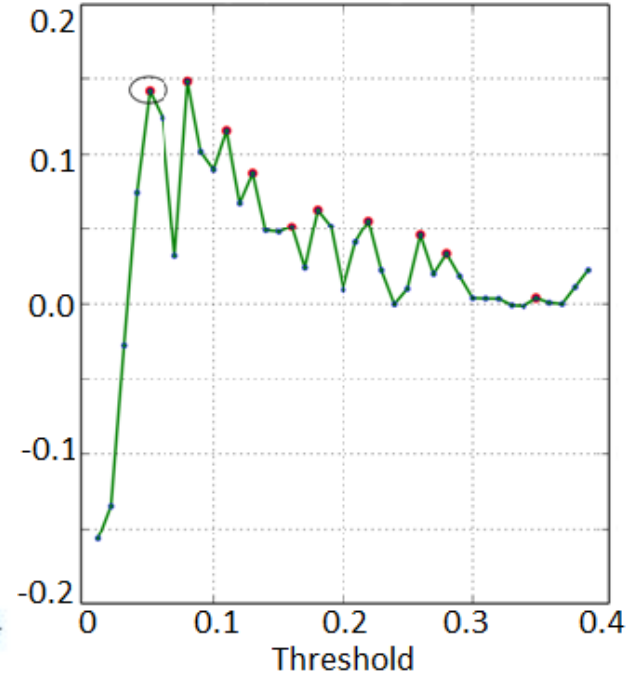

(b)

Fig 5 ROC-LV graph of Can Tho area of (a) whole area and (b) built-up set. Threshold 0.04 and 0.05 are selected for segmentation respectively. 


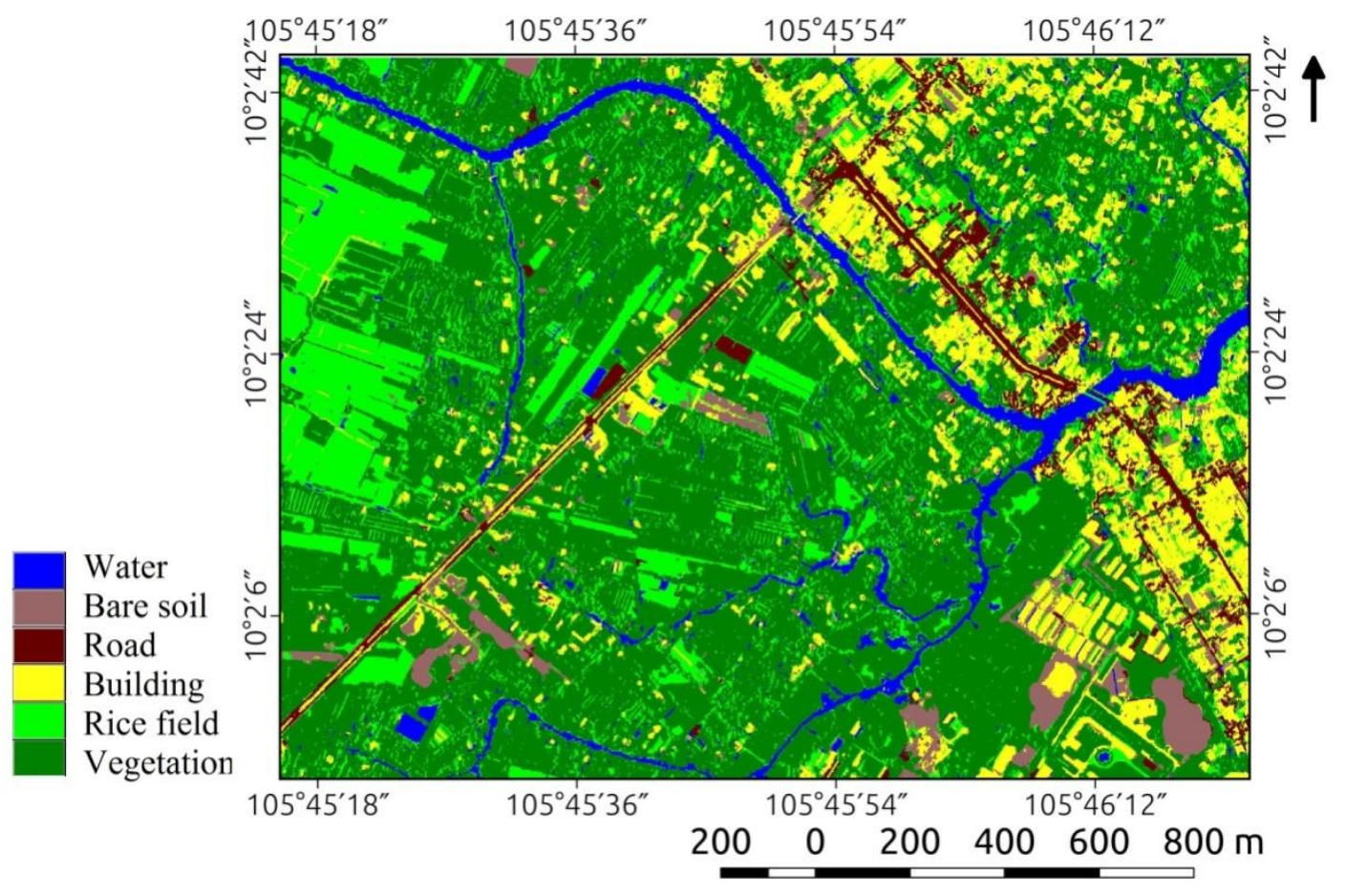

Fig 6 Can Tho LULC map 
Table 1 Rule of Fuzzy classification of Lao Cai area

\begin{tabular}{|c|c|c|c|}
\hline Level & ID & Class/ set & Rule \\
\hline \multirow[t]{4}{*}{ Whole area } & R1 & Water & $\begin{array}{l}\text { (NDVI is low \& WI is high) or (NDWI is high \& WI is high) or(NDVI } \\
\text { is moderate \& NDWI is low \& WI is high) }\end{array}$ \\
\hline & R2 & Built-up set & $\begin{array}{l}\text { (NDVI is moderate \& NDWI is low \& WI is low) or (NDVI is low \& } \\
\text { NDWI is low \& WI is low) or (NDVI is high \& NDWI is low \& blue } \\
\text { band is high) }\end{array}$ \\
\hline & $\mathrm{R} 3$ & Terrace field & NDVI is high \& NDWI is low \& blue band is low \\
\hline & R4 & Vegetation set & NDVI is very high \& NDWI is low \\
\hline \multirow[t]{3}{*}{ Built-up set } & R5 & Building & $\begin{array}{l}\text { (WI is moderate \& SI is moderate) or (WI is moderate \& SI is moderate } \\
\& \mathrm{SmI} \text { is low) }\end{array}$ \\
\hline & R6 & Road & WI is moderate \& SI is moderate \& SmI is high \\
\hline & R7 & Bare land & WI is high or SI is low or WI is low or SI is high \\
\hline \multirow[t]{2}{*}{ Vegetation set } & R8 & Paddy field & NDVI is low \& RedEgde band is high \\
\hline & R9 & Forest & NDVI is high or (NDVI is low \& RedEgde band is low) \\
\hline
\end{tabular}

Table 2 Confusion matrix of Lao Cai

\begin{tabular}{lrlrrrrrl}
\hline \multicolumn{1}{c}{ Class } & Water & $\begin{array}{l}\text { Bare } \\
\text { Land }\end{array}$ & Road & Building & $\begin{array}{l}\text { Paddy } \\
\text { field }\end{array}$ & $\begin{array}{l}\text { Terrace } \\
\text { field }\end{array}$ & Forest \\
& Water & 5130 & 295 & 3 & 0 & 0 & 0 & 0 \\
Bare land & 126 & 2646 & 107 & 322 & 0 & 29 & 0 & \\
Building & 0 & 32 & 1109 & 308 & 0 & 21 & 0 & \\
Road & 10 & 87 & 379 & 4362 & 1 & 174 & 367 & \\
Paddy field & 0 & 0 & 1 & 1 & 3735 & 263 & 2761 & \\
Terrace field & 28 & 136 & 9 & 48 & 20 & 3695 & 389 & \\
Forest & 1 & 9 & 0 & 0 & 256 & 20 & 40419 & \\
Sum & 5295 & 3205 & 1608 & 5041 & 4012 & 4202 & 43936 & OA: 90.8\% \\
Accuracy (\%) & $\mathbf{9 6 . 9}$ & $\mathbf{8 2 . 6}$ & $\mathbf{6 9 . 0}$ & $\mathbf{8 6 . 5}$ & $\mathbf{9 3 . 1}$ & $\mathbf{8 7 . 9}$ & $\mathbf{9 2 . 0}$ & Kappa: 0.84 \\
\hline
\end{tabular}

Table 3 Rule of Fuzzy classification of Can Tho area

\begin{tabular}{|c|c|c|c|}
\hline \multicolumn{4}{|r|}{ Can Tho } \\
\hline Level & ID & Class/ set & Rule \\
\hline \multirow[t]{4}{*}{ Whole area } & R10 & Water & WI is high \\
\hline & R11 & Vegetation & WI is low \& NDWI is low \\
\hline & R12 & Built-up set & WI is low \& NDWI is high \\
\hline & R13 & \multirow[t]{2}{*}{ Paddy field } & WI is moderate \\
\hline \multirow[t]{4}{*}{ Built-up set } & R14 & & blue band is low \& SI is low \& SmI is low \\
\hline & R15 & Road & NDWI is high \& blue band is high \& SmI is high \\
\hline & R16 & Bare land & NDWI is low \& blue band is high \& SI is moderate \\
\hline & $\mathrm{R} 17$ & Building & $\begin{array}{l}\text { NDWI is high \& blue band is high \& SmI is low) or (blue band is low } \\
\text { \& SI is moderate) or (blue band is low \& SI is high) or (blue band is } \\
\text { low \& SI is low \& SmI is high) or (blue band is high \& NDWI is low \& } \\
\text { SI is low) or (blue band is high \& NDWI is low \& SI is high) }\end{array}$ \\
\hline
\end{tabular}


Table 4 Confusion matrix of Can Tho data

\begin{tabular}{lrrrrrrr}
\cline { 1 - 5 } \multicolumn{1}{c}{ Class } & Water & \multicolumn{1}{c}{ Bare land } & \multicolumn{1}{c}{ Road } & Building & Paddy field & Vegetation \\
\cline { 1 - 5 } Water & 11199 & 0 & 0 & 7 & 90 & 150 & \\
Bare land & 2 & 2821 & 437 & 570 & 152 & 16 & \\
Road & 3 & 409 & 6128 & 1378 & 0 & 0 & \\
Building & 4 & 155 & 444 & 9840 & 2 & 191 \\
Paddy field & 115 & 19 & 101 & 490 & 12616 & 1649 & \\
Vegetation & 9 & 41 & 2 & 55 & 155 & 36077 & \\
Sum & 11332 & 3445 & 7112 & 12268 & 13015 & 38083 & OA: 92.3 \% \\
Accuracy (\%) & $\mathbf{9 8 . 8}$ & $\mathbf{8 1 . 9}$ & $\mathbf{8 6 . 2}$ & $\mathbf{8 0 . 2}$ & $\mathbf{9 6 . 9}$ & $\mathbf{9 4 . 7}$ & Kappa: 0.90 \\
\hline
\end{tabular}

